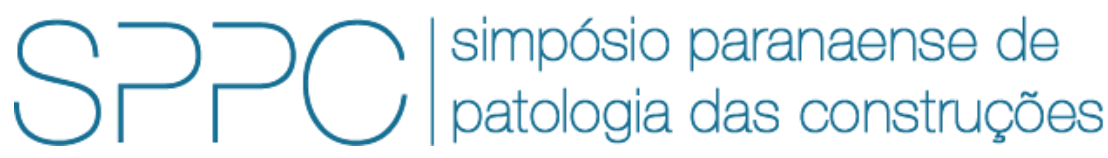

ISSN 2526-7248 artigo 2SPPC1034, pp. 406-420, 2017

\title{
Avaliação da variação dimensional de corpos de prova de argamassa de diferentes tipos de cimentos submetidos ao ataque por ácido sulfúrico e sulfato de sódio
}

Marion Scheffer de Andrade Silva ${ }^{1}$, Adriano Mohr Bonatto ${ }^{2}$, Juliana Janowski Zandoná ${ }^{3}$, Jayson Pereira Godinho ${ }^{4}$, Luís César Siqueira de Luca ${ }^{5}$, Marcelo Henrique Farias de Medeiros ${ }^{6}$

1Eng. Civil, Mestranda em Eng. de Construção Civil (PPGECC), UFPR, mari125@gmail.com.

2Eng. Civil, Especialista de OAEs na Rumo Logística, adrianombonatto@yahoo.com.br

${ }^{3}$ Eng. Civil, Especialista em Patologia nas Obras Civis (Instituto IDD), responsável técnico na Construtora e Incorporadora Laguna, juliana.zandona@outlook.com

${ }^{4}$ Eng. Ambiental, Mestre em Ciência e Tecnologia Ambiental (UTFPR), doutorando em Eng. de Construção Civil (PPGECC), UFPR, jayson.godinho.eng@gmail.com.

${ }^{5}$ Eng. Civil, Mestre em Eng. Civil (UFSC), Instituto IDD, campus Curitiba, deluca@idd.com.br

${ }^{6}$ Eng. Civil, Mestre e Doutor em Eng. Civil (USP), UFPR, marcelo.ufpr@gmail.com.

Resumo: Neste trabalho, foi realizada uma avaliação da variação dimensional de corpos de prova de argamassa moldados com diferentes tipos de cimento submetidos ao ataque ácido de agentes compostos de enxofre com o intuito de avaliar o comportamento entre três tipos de cimento a essas agressões. Dentre os corpos de prova moldados, foram utilizados três tipos diferentes de cimento, sendo esses o cimento Portland (CP) II Z, CP IV-32 RS e CPV. Os ensaios foram realizados submetendo um terço dos corpos de prova à solução de sulfato de sódio, um terço dos corpos de prova à solução de ácido sulfúrico com concentração $1 \%$ e um terço à solução de água saturada com cal, para referência. Após a cura dos corpos de prova, foi realizada a medida inicial dos mesmos em um relógio comparador e foram realizadas medições posteriores após determinados períodos de imersão nas soluções. As medições para avaliar a variação dimensional foram realizadas aos $14,28,51,58,63,72,79$ e 95 dias. As amostras com cimento CP II-Z apresentaram maior variação dimensional relativa e a menor variação dimensional relativa foi obtida com as amostras de cimento CP IV $32 \mathrm{RS}$. O pH da solução de referência e da solução de sulfato de sódio só apresentou variação a partir da medição de 63 dias. Foi observada a maior variação do $\mathrm{pH}$ pela solução de ácido sulfúrico e houve necessidade de corrigir o pH da solução nas primeiras semanas de imersão.

Palavras-chave: Ataque ácido, Ataque por sulfatos, Variação dimensional.

Abstract: In this work, an evaluation of the dimensional variation of mortar specimens molded with different types of cement subjected to acid attack of composite sulphur agents was carried out in order to evaluate the difference between the different types of cement to these aggressions. Among the molded specimens, three different types of cement were used, and these were CP II Z, CP IV-32 RS and CPV. The tests were carried out by submitting part of the test specimens to the sodium sulfate solution, another part of the test specimens in sulfuric acid and the third part in solution of water with lime for reference. After the curing time of the specimens, the initial measurement of the specimens was carried out in a comparator watch and subsequent immersion in the solutions. Measurements to evaluate the dimensional variation were performed at $14,28,51,58,63,72,79$ e 95 days. The type of cement that presented the largest dimensional variation was the CP II-Z, being the smallest the CP IV 32 RS. The $\mathrm{pH}$ variation of the reference solution and the sodium sulfate solution had only divergence for the different cements after the $63^{\text {th }}$ day of measurement. A greater aggression was observed for the sulfuric acid solution, since it was necessary to carry out correction in the $\mathrm{pH}$ of the solution in the first measurements.

Keywords: Acid attack, Sulphate attack, Dimensional variation 


\section{Introdução}

A deterioração e os riscos do ataque químico às estruturas de concreto representam uma motivação para o desenvolvimento de pesquisas nessa área. Dentre os fatores que podem contribuir para deterioração das estruturas de concreto estão: a agressividade do meio no qual as estruturas estão inseridas são, as propriedades químicas do meio agressivo, concentração e tipo de substância agressiva, a taxa relativa entre o volume de meio agressivo e volume de material atacado, o meio de contato entre o meio e o material [1]

Dentre os meios agressivos aos quais as estruturas estão expostas, o ataque por sulfatos é um desses meios e o mecanismo pode ocorrer pelo contato entre estruturas de concreto e ambientes que contenham sulfato, tais como solos, águas subterrâneas que possuem em sua concentração sulfato de magnésio, sódio e potássio. $O$ ataque por sulfatos ao concreto pode se manifestar por expansão ou fissuração, podendo levar ao aumento da permeabilidade do concreto, problemas estruturais e iniciar processos de corrosão das armaduras [2]. Sendo que o ataque ácido pode se manifestar pelos mesmos sintomas de expansão e fissuração. Desta maneira, é necessário compreender o ambiente no qual a estrutura está inserida para verificar compreender o mecanismo de degradação a mesma está envolvida.

A NBR 6118 [3] é a norma técnica com especificação para elaboração de projetos de estruturas de concreto, porém, esta norma contém apenas informações quanto ao tipo de cimento utilizar para mitigar o ataque por sulfatos, e não é especifica quanto aos outros materiais ou outros mecanismos de ataque. As especificações apenas remetem a algumas propriedades dos materiais utilizando o quesito de classificação por agressividade ambiental e então delimitam a resistência à compressão mínima, fator água/cimento máximo e o cobrimento mínimo das armaduras. Em outra parte da NBR 6118 [3] é especificado que para prevenir a expansão por sulfatos, deve-se utilizar um cimento resistente a sulfatos, sendo este regulamentado pela NBR 5737 [4] e é especificado ainda um ensaio pela NBR 13853 [5] para verificar se o cimento é resistente a sulfatos ou não. As normas técnicas não especificam as características deste tipo de estrutura quanto ao tipo de agregado que deve ser utilizado, tipo de impermeabilização ou até mesmo outras especificações para essas estruturas em particular. E também não especificam os materiais que devem ser usados para estruturas expostas a soluções ácidas.

Visto que há lacunas quanto às especificações técnicas de materiais para esse tipo de estrutura, é importante que os estudos nessa área sejam realizados com o intuito de entender os processos de degradação nestas estruturas e assim gerar conhecimento cientifico e técnico acerca dos materiais que atendam mais satisfatoriamente as características de vida útil nestes microclimas.

A diferença entre as soluções de exposição é a severidade do ataque resultante, sendo, por exemplo, o ácido sulfúrico mais severo do que o sulfato de magnésio e esse mais severo do que o sulfato de sódio [6]. Assim como, 
diferentes soluções de sulfatos resultam em diferentes severidades de ataque, materiais com composições podem interação distinta com as soluções.

Assim, a presente pesquisa teve o objetivo de avaliar a influência do tipo de cimento na variação dimensional de corpos de prova de argamassa expostos ao ataque por soluções agressivas de ácido sulfúrico e compará-lo aos corpos de prova de argamassa expostos a solução de sulfato de sódio.

\section{Material e Métodos}

\subsection{Programa experimental}

O programa experimental foi executado de acordo com o preconizado pela NBR 13583 [5], utilizando os corpos de prova de argamassa prismáticos de 2,5 x 2,5 x 28,5 cm de acordo com o especificado pela norma. Foram usados diferentes tipos de cimento (CP II Z, CP IV-32 RS e CPV-ARI) e os corpos de prova foram expostos a soluções agressivas de sulfato de sódio, assim como especificado pela norma e solução de ácido sulfúrico, com concentração de $1 \%$ e pH inicial de 2,0. Foram realizadas medições da expansão ao longo do tempo de exposição dos corpos de prova e foram realizadas análises visuais dos corpos de prova nas idades em que as medições foram realizadas.

Uma vez que o ensaio de variação dimensional com ácido sulfúrico não é normatizado, foram moldados dois corpos de prova a mais do que os quatro especificados pela NBR 13853 [5]. No entanto, após a moldagem houve a quebra de três corpos de prova de CP IV-32 RS, desta maneira, foram utilizados cinco corpos de prova por série para este tipo de cimento, enquanto para os demais a quantidade de seis corpos de prova foi mantida. A quantidade final de corpos de prova utilizados está descrita na Tabela 1.

Tabela 1: Quantidade de corpos de prova

\begin{tabular}{ccccc}
\hline Cimento & Água & $\begin{array}{c}\text { Ácido } \\
\text { sulfúrico }\end{array}$ & $\begin{array}{c}\text { Sulfato de } \\
\text { Sódio }\end{array}$ & Total \\
\hline CP II Z & 6 & 6 & 6 & 18 \\
CP IV-32 RS & 5 & 5 & 5 & 15 \\
CP V & 6 & 6 & 6 & 18 \\
\hline \multicolumn{7}{c}{ Total } & & 51 \\
\hline
\end{tabular}

Foram usados no ensaio um total de 51 corpos de prova expostos a três diferentes soluções, sendo a solução de água saturada com cal a solução de referência. Além disso, foram utilizados três tipos de cimento, sendo o CP IV RS preconizado pelas normas técnicas para ambientes sujeitos ao ataque por sulfatos

Pelo fato da atividade pozolânica se estender nas idades iniciais de concretos e argamassas, decidiu-se estender também o tempo de cura dos corpos de prova deste trabalho em comparação ao tempo previsto em norma, para que as reações pozolânicas fossem mínimas. Se o corpo de prova fosse submetido à solução agressiva após $48 \mathrm{~h}$ conforme previsto em norma, ao mesmo tempo em que as reações estariam acontecendo, este estaria sendo atacado. 
Deste modo o período de cura adotado foi de 104 dias para todos os corpos de prova expostos à solução de sulfato de sódio e água saturada com cal e de 155 dias para os corpos de prova expostos à solução de ácido sulfúrico com concentração de $1 \%$.

Os procedimentos para o ensaio de variação dimensional dos $\mathrm{cp}$ tiveram como base a metodologia proposta pela NBR 13583 [5]. Como a solução de ácido sulfúrico é muito agressiva e não há norma para este ensaio, o tempo para primeira medição foi adaptado para 7 dias, ao invés de 14 dias como preconizado pela norma, para garantir que os dados verificassem a variação dimensional, já que os corpos de prova apresentam ataque visível desde os primeiros dias de imersão. Como o ataque por soluções de ácido sulfúrico é acelerado, foi feita uma medição intermediária entre as datas previstas para medição na norma de 14 e 28 dias e foi feita uma medição aos 21 dias de idade.

A norma prevê a medição dos corpos de prova com 42 dias de imersão em solução agressiva, porém neste trabalho os corpos de prova expostos à solução de sulfato de sódio foram medidos aos 51 dias, e os corpos de prova imersos em solução de ácido sulfúrico precisaram ser medidos aos 44 dias.

Passado o prazo previsto em norma, foram feitas medições para os corpos de prova imersos em solução de sulfato de sódio nas idades mostradas - Tabela 2. As medições nas idades superiores a 44 dias não foram feitas para os corpos de prova imersos em solução de ácido sulfúrico.

Tabela 2: Idades de medição dos corpos de prova.

\begin{tabular}{cccccccccccc}
\hline Solução & $\begin{array}{c}7 \\
\text { dias }\end{array}$ & $\begin{array}{c}14 \\
\text { dias }\end{array}$ & $\begin{array}{c}21 \\
\text { dias }\end{array}$ & $\begin{array}{c}28 \\
\text { dias }\end{array}$ & $\begin{array}{c}44 \\
\text { dias }\end{array}$ & $\begin{array}{c}51 \\
\text { dias }\end{array}$ & $\begin{array}{c}58 \\
\text { dias }\end{array}$ & $\begin{array}{c}63 \\
\text { dias }\end{array}$ & $\begin{array}{c}72 \\
\text { dias }\end{array}$ & $\begin{array}{c}79 \\
\text { dias }\end{array}$ & $\begin{array}{c}95 \\
\text { dias }\end{array}$ \\
\hline $\begin{array}{c}\text { Sulfato de } \\
\begin{array}{c}\text { sódio } \\
\text { Ácido }\end{array}\end{array}$ & SIM & & SIM & & SIM & SIM & SIM & SIM & SIM & SIM \\
$\begin{array}{c}\text { sulfúrico } \\
\text { SulM }\end{array}$ & SIM & SIM & SIM & SIM & & & & & & \\
\hline
\end{tabular}

Foram feitas as medições em todas as idades para a solução de água saturada com cal, para que fosse possível calcular a variação resultante.

\subsection{Caracterização dos materiais}

Tendo em vista o objetivo da pesquisa, foram adotados para a realização dos ensaios três tipos de cimento diferentes disponíveis no mercado nacional. Desta forma, foi possível comparar o desempenho de cada tipo de cimento quando exposto a soluções agressivas.

\subsubsection{Cimento}

Os tipos de cimento escolhidos foram o CP IV-32 RS, que possui a maior quantidade de material pozolânico dentre os cimentos selecionados (sendo 0 valor usual de 15 a 50\%), o CP II Z que também possui em sua composição material pozolânico, porém em um percentual mais baixo (sendo o valor usual 
SILVA,M. S. A.; ET AL. AVALIAÇÃO DA VARIAÇÃO DIMENSIONAL DE CORPOS DE PROVA DE ARGAMASSA DE DIFERENTES TIPOS DE CIMENTO SUBMETIDOS AO ATAQUE POR ÁCIDO SULFÚRICO E SULFATO DE SÓDIO. $2^{\circ}$

Simpósio Paranaense de Patologia das Construções (20 SPPC), artigo 2SPPC1034, pp. 406-420, 2017. DOI: $10.4322 / 2$ SPPC. 2017.034

de 6 a 14\%) e o CP V ARI, que tem uma moagem mais fina e tem a característica de atingir elevada resistência inicial.

\subsubsection{Agregado Miúdo}

O agregado miúdo utilizado foi areia média natural peneirada, da região metropolitana de Curitiba, que foi seca a $105^{\circ} \mathrm{C}$ até apresentar constância de massa.

A caracterização do agregado miúdo foi obtida de acordo com o preconizado pela NBR 7211 [7], com a apresentação dos parâmetros tais como, massa específica $\left(\mathrm{g} . \mathrm{cm}^{-3}\right)$, massa unitária $\left(\mathrm{g} . \mathrm{cm}^{-3}\right)$, módulo de finura, teor de material pulverulento (\%).

\subsection{Ensaios de variação dimensional}

\subsubsection{Realização do ensaio}

O traço utilizado para os ensaios foi $1: 3,2: 0,6$. Os moldes foram prismáticos de 25x25x285mm, conforme previsto na NBR 13583 [5]. Os pinos de aço inoxidável foram ajustados antes do preenchimento dos moldes.

Após a moldagem dos corpos de prova, os mesmos foram deixados em cura antes de serem colocados em imersão. Para a imersão, os corpos de prova foram colocados em recipientes montados com tubos de PVC de $150 \mathrm{~mm}$, como CAP também de PVC para que fossem deixados imersos na solução e aquecidos em banho-maria para que a temperatura fosse mantida.

Após isso, os corpos de prova foram colocados em caixas de plástico, separando as amostras por tipo de cimento e tipo de solução, e foram colocados na estufa a temperatura constante de $40^{\circ} \mathrm{C}$. Como apoio para os corpos de prova, para que os mesmos não tocassem o fundo, foram utilizadas canaletas do tipo "sistema X", que são comumente utilizadas para realizar instalação elétrica, para apoiar as duas extremidades do corpo de prova.

Antes da colocação da tampa do recipiente, o mesmo era coberto com papel filme de plástico para evitar que a solução evaporasse com o calor.

A NBR 13583 [5] preconiza que as barras sejam medidas em um extensômetro nas idades de 14, 28 e 42 dias. Neste trabalho, foi feita a medição foi iniciada aos 7 dias, já que o ácido sulfúrico é mais agressivo e começaria e danificar a peça mais rápido que o sulfato de sódio, e foram ultrapassados os 42 dias, para melhorar os dados estatísticos.

\subsubsection{Análise visual}

Conforme descrito na NBR 13583 [5], deve-se analisar, nas idades de medição, o aspecto visual das barras, registrando toda e qualquer anomalia apresentada, tais como: fissuração das barras, o tamanho e intensidade das fissuras, desagregação parcial, total ou empenamento das barras, alterações na temperatura de cura ao longo do ensaio, evaporação da água de imersão, com 
SILVA,M. S. A.; ET AL. AVALIAÇÃO DA VARIAÇÃO DIMENSIONAL DE CORPOS DE PROVA DE ARGAMASSA DE DIFERENTES TIPOS DE CIMENTO SUBMETIDOS AO ATAQUE POR ÁCIDO SULFÚRICO E SULFATO DE SÓDIO. $2^{\circ}$

Simpósio Paranaense de Patologia das Construções (20 SPPC), artigo 2SPPC1034, pp. 406-420, 2017. DOI:

necessidade de complementação, impossibilidade de leitura com 0 extensômetro e, portanto, emprego de paquímetro ou outro instrumento de medida.

Desta forma, é possível analisar manifestações patológicas resultantes do ataque do sulfato de sódio e do ácido sulfúrico, assim como analisar a diferença de comportamento de cada tipo de cimento quando exposto a estes elementos. Todas as barras foram fotografadas em todas as idades.

\subsubsection{Ensaio de determinação da variação de massa}

Os ensaios de alteração de massa são comuns em experimentos que utilizam ataque ácido, mas os mesmos dependem do tipo de cimento e do tamanho da amostra, que pode ser influenciada pelas reações de expansão que ocorrem quando a estrutura começa a ser degradada. As ações combinadas de dissolução e expansão que ocorrem gradualmente na camada superficial de argamassa provocam a redução significativa da massa dos cilindros [8].

Girardi, Vaona e Di Maggio [9] realizaram um ensaio no qual verificaram a perda de massa e expansão de corpos de prova de concreto, submetidos ao ataque cíclico de sulfato de sódio e ácido sulfúrico, com variações no tipo de cimento e nas adições. Com os resultados, verifica-se que, nas amostras que apresentaram menor expansão, a taxa de perda de massa foi maior, logo, ambos os fatores devem ser considerados no projeto e no estudo de estruturas.

No procedimento descrito por Girardi, Vaona e Di Maggio [9] os corpos de prova são pesados antes da imersão e ao final do ensaio, quando os corpos de prova são retirados da imersão. Neste experimento, os corpos de prova foram pesados anteriormente ao ensaio e a cada medição de expansão realizada, para verificar a variação de massa, e, após a finalização do ensaio de variação dimensional, os corpos de prova seriam secos e pesados novamente.

\section{Resultados e discussões}

\subsection{Caracterização dos materiais}

Os resultados de caracterização dos materiais estão apresentados nas Tabela 3, que contém a caracterização do cimento; e Tabela 4, com caracterização do agregado miúdo.

\subsubsection{Cimento}

A partir da Tabela 3, é possível verificar que os cimentos utilizados foram o Cimento Portland CP II Z 32, CP IV RS e CP V ARI, cujas composições químicas, físicas e mecânicas são informadas na especificação do fabricante. 
SILVA,M. S. A.; ET AL. AVALIAÇÃO DA VARIAÇÃO DIMENSIONAL DE CORPOS DE PROVA DE ARGAMASSA DE DIFERENTES TIPOS DE CIMENTO SUBMETIDOS AO ATAQUE POR ÁCIDO SULFÚRICO E SULFATO DE SÓDIO. $2^{\circ}$

Simpósio Paranaense de Patologia das Construções (20 SPPC), artigo 2SPPC1034, pp. 406-420, 2017. DOI:

Tabela 3: Caracterização do cimento CP II Z, CP IV e CP V ARI.

\begin{tabular}{l|c|c|c}
\hline \multirow{2}{*}{\multicolumn{1}{c|}{ Componente }} & \multicolumn{3}{c}{ Tipo de cimento } \\
\cline { 2 - 4 } & CP II Z & CP IV RS & CP V \\
\hline $\mathrm{Al}_{2} \mathrm{O}_{3}(\%)$ & - & 9,76 & 4,41 \\
\hline $\mathrm{SiO}_{2}(\%)$ & - & 29,07 & 18,9 \\
\hline $\mathrm{Fe}_{2} \mathrm{O}_{3}(\%)$ & - & 3,85 & 2,70 \\
\hline $\mathrm{CaO}(\%)$ & 54,67 & 45,12 & 60,55 \\
\hline $\mathrm{MgO}(\%)$ & 5,53 & 2,92 & 4,49 \\
\hline $\mathrm{SO}_{3}(\%)$ & 2,98 & 2,25 & 2,59 \\
\hline Perda ao fogo (\%) & - & - & 3,1 \\
\hline Resíduo insolúvel (\%) & 12,52 & 25,44 & 0,83 \\
\hline Equivalente alcalino (\%) & 0,86 & 1,14 & 0,65 \\
\hline Expansibilidade a quente (\%) & 0,58 & 0,30 & 0,17 \\
\hline Tempo de Pega (Início) & $4: 47$ & $04: 29$ & $3: 16$ \\
\hline Tempo de Pega (Fim) & $5: 59$ & $5: 15$ & $3: 53$ \\
\hline Consistência normal (\%) & 27,7 & 29,9 & 28,9 \\
\hline Blaine (cm².-1) & 3553 & 4171 & 3978 \\
\hline \#200 (\%) & 1,62 & 0,46 & 0,14 \\
\hline \#325 (\%) & 11,04 & 2,71 & 01,78 \\
\hline Resistência à compressão & 37,23 & 45,3 & 51,9 \\
\hline (MPa) aos 28 dias & 2,98 & 2,82 & 3,09 \\
\hline Massa específica (g/cm²) & & &
\end{tabular}

\subsubsection{Agregado miúdo}

O agregado miúdo apresentou resultados adequados ao ensaio, uma vez que a zona granulométrica da areia utilizada foi zona ótima e a norma especifica que a areia utilizada deve ser areia média. De acordo com os resultados obtidos, foi verificado que o módulo de finura da areia utilizada é 2,63 e está de acordo com a especificação para areia do tipo médio. Os resultados da caracterização estão apresentados na Tabela 4.

Tabela 4: Caracterização do agregado miúdo

\begin{tabular}{c|c|c}
\hline Parâmetros & Resultado & Norma \\
\hline Massa especifica $\left(\mathrm{g}^{\left.-\mathrm{cm}^{-3}\right)}\right.$ & $\mathrm{E} 1=2,595 ; \mathrm{E2}=2,595$ & NBR NM 52 [10] \\
\hline Massa unitária $\left(\mathrm{g} \cdot \mathrm{cm}^{-3}\right)$ & $\mathrm{E} 1=1,612 ; \mathrm{E2}=1,605$ & NBR NM 45 [11] \\
\hline Módulo de finura & 2,63 & NBR NM 248 [12] \\
\hline Teor de material pulverulento (\%) & $\mathrm{E} 1=2,53 ; \mathrm{E2}=2,62$ & NBR NM 46 [13] \\
\hline Composição granulométrica & Zona ótima (Figura 1) & NBR NM 248 [12]
\end{tabular}

A Figura 1 apresenta os resultados do ensaio referente à distribuição granulométrica do agregado miúdo, realizado com base na norma técnica referenciada na Tabela 4.

\subsection{Análise da variação dimensional}

Após a cura dos corpos de prova, foi realizada a medição inicial dos mesmos em um relógio comparador. A NBR 13853 [5] especifica que as medições 
SILVA,M. S. A.; ET AL. AVALIAÇÃO DA VARIAÇÃO DIMENSIONAL DE CORPOS DE PROVA DE ARGAMASSA DE DIFERENTES TIPOS DE CIMENTO SUBMETIDOS AO ATAQUE POR ÁCIDO SULFÚRICO E SULFATO DE SÓDIO. $2^{\circ}$

Simpósio Paranaense de Patologia das Construções (20 SPPC), artigo 2SPPC1034, pp. 406-420, 2017. DOI: 10.4322/2SPPC.2017.034

sejam realizadas nas datas de 14, 28 e 42 dias, porém, não foi possível realizar as medidas aos 42 dias e foi necessário realizá-las aos 51 dias. Além disso, para as soluções de sulfato de sódio e de água saturada com cal foram, também foram realizados ensaios de análise do comportamento dos corpos de prova aos 58 dias, 63 dias, 72 dias, 79 dias e 93 dias.

Com as medições realizadas foi obtida a expansão média dos corpos de prova. Para os corpos de prova de cimento CP V e cimento CP II Z, a média foi calculada com os valores de seis corpos de prova. Para os corpos de prova de cimento CP IV-32 RS, a média foi calculada com os valores de cinco corpos de prova.

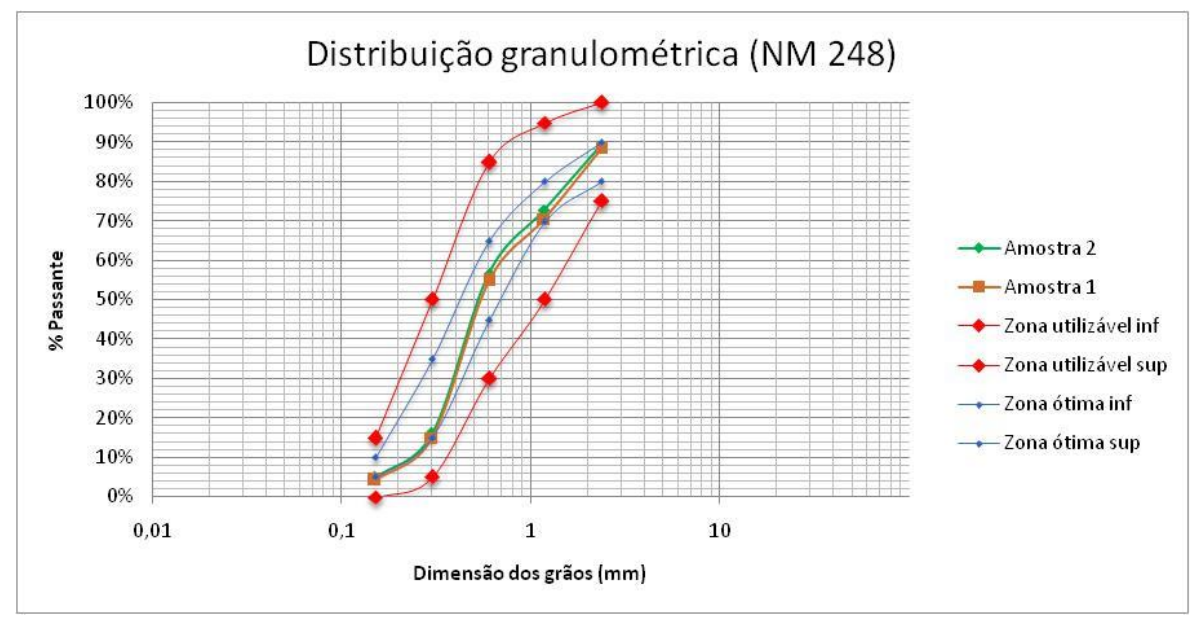

Figura 1: Curva granulométrica do agregado miúdo utilizado

De acordo com a NBR 13583 [5], para expansões resultantes menores do que $0,02 \%$, o valor da expansão é desconsiderado no cálculo da média quando difere em até $0,03 \%$. No entanto, para expansões maiores do que $0,02 \%$, se 0 valor diferir em até $15 \%$ da média, o mesmo deve ser desconsiderado para 0 cálculo da média e deverá ser realizado o cálculo de uma nova média sem esse valor.

Para obter a expansão resultante é feito um cálculo do valor de expansão da solução agressiva (Es), seja ela de sulfato de sódio ou de ácido sulfúrico em relação à expansão de água saturada com cal (Ea). Com esses valores foi possível verificar a expansão resultante $(\mathrm{Ae})$ dos corpos de prova.

$$
\mathrm{Ae}=\mathrm{Es}-\mathrm{Ea}(\%) \quad(\text { Equação } 1)
$$

Os valores de expansão resultante para este ensaio estão apresentados na Tabela 5.

Além disso, a variação retração/expansão para o cimento CP IV-32 RS foi menor do que para os demais cimentos, quando expostos a solução de ácido sulfúrico, uma vez que o valor de expansão aos 7 dias foi 0,125 e o de expansão aos 44 dias foi de 0,308, logo, a variação dimensional entre um período e outro foi de aproximadamente 0,183 .

Para os corpos de prova de argamassa de cimento $\mathrm{CP} V$, a variação dimensional resultante obtida aos 7 dias foi - 0,407 e a variação dimensional 
resultante aos 51 dias foi de 0,922 . Logo, a variação dimensional resultante no período foi de 1,32 .

Os corpos de prova expostos à solução de ácido sulfúrico que tiveram maior variação dimensional resultante foram os corpos de prova de cimento CP II Z, os quais apresentaram expansão resultante de 0,127 aos 7 dias, expansão resultante aos 1,259 aos 44 dias, sendo a variação dimensional resultante no período 1,132 .

Foi verificado que a variação dimensional para o cimento $C P \quad V$ foi aproximadamente sete vezes maior do que a variação dimensional do CP IV-32 RS. E a variação dimensional para o CP II Z em relação do CP IV-32 RS foi cinco vezes maior.

\subsection{Variação de massa}

A avaliação da variação de massa foi realizada para verificar a se os corpos de CP II Z tiveram maior ou menor perda de massa com a expansão. Verificou-se que as amostras atacadas por ácido sulfúrico apresentaram pH da solução com maior variação, o que indicaria que os compósitos do cimento estariam sendo dissolvidos pela solução. Outro fenômeno que pode ocorrer é o ganho de massa, pela formação de compostos expansivos ou preenchimento dos poros do concreto com solução. Foi verificado o aumento da massa dos corpos de prova, como é possível observar na Figura 5, no entanto, não é possível concluir se esse aumento de massa ocorreu devido ao preenchimento dos poros pela solução ou pela formação de produtos expansivos. 
Tabela 5: Variação dimensional resultante dos corpos de prova de argamassa com diferentes tipos de cimento.

\begin{tabular}{|c|c|c|c|c|c|c|c|c|c|c|c|}
\hline \multicolumn{12}{|c|}{ Variação Dimensional Resultante (\%) } \\
\hline \multirow{2}{*}{ Solução } & 7 dias & 14 dias & 21 dias & 28 dias & 44 dias & 51 dias & 58 dias & 63 dias & 72 dias & 79 dias & 95 dias \\
\hline & \multicolumn{11}{|c|}{ Cimento CP V } \\
\hline Sulfato de sódio & - & 0,003 & - & $-0,018$ & - & 0,012 & 0,055 & 0,097 & $-0,069$ & 0,003 & 0,148 \\
\hline Ácido sulfúrico & $-0,407$ & $-0,012$ & $-0,023$ & $-0,078$ & 0,922 & - & - & - & - & - & - \\
\hline Solução & \multicolumn{11}{|c|}{ CP IV-32 RS } \\
\hline Sulfato de sódio & - & 0,013 & - & 0,049 & - & 0,037 & 0,055 & 0,019 & 0,041 & 0,028 & 0,045 \\
\hline Ácido sulfúrico & 0,125 & 0,352 & 0,363 & 0,283 & 0,308 & - & - & - & - & - & - \\
\hline Solução & \multicolumn{11}{|c|}{ Cimento CP II Z } \\
\hline Sulfato de sódio & - & 0,001 & - & 0,006 & - & 0,209 & 0,022 & 0,264 & 0,362 & 0,338 & $-0,444$ \\
\hline Ácido sulfúrico & 0,127 & $-0,392$ & 0,280 & 1,175 & 1,259 & - & - & - & - & - & - \\
\hline
\end{tabular}

Nas Figura 2, Figura 3 e Figura 4 verifica-se que os corpos de prova de argamassa imersos na solução de ácido sulfúrico tiveram maior variação dimensional resultante do que os corpos de prova de argamassa expostos à solução de sulfato de sódio.

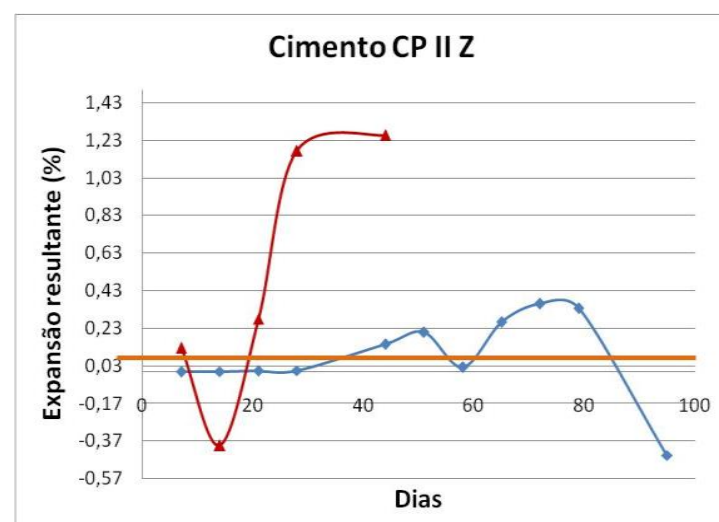

Figura 2: Expansão resultante para os corpos de prova de CPII Z

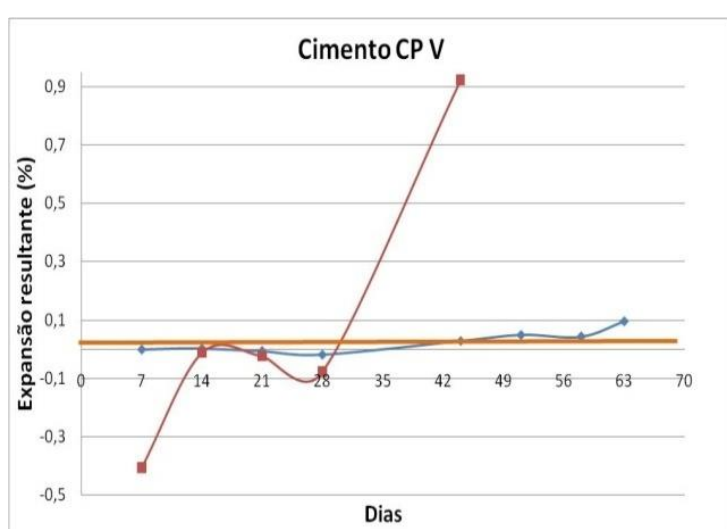

Figura 3: Expansão resultante para os corpos de prova de CP V

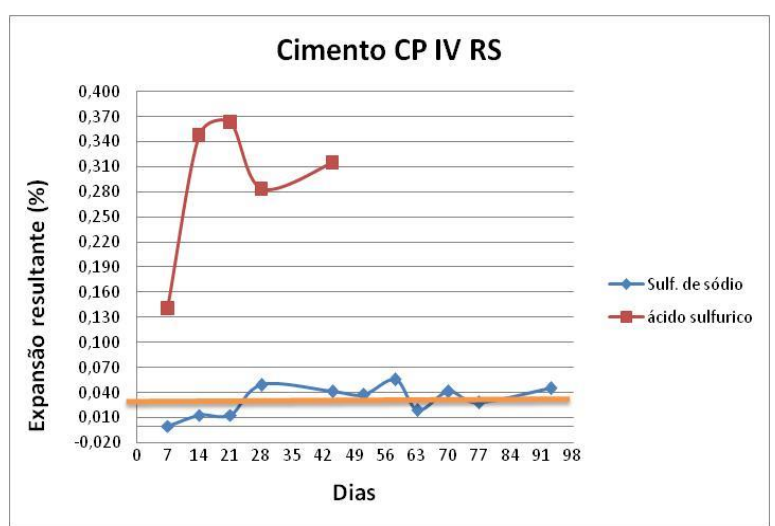

Figura 4 - Expansão resultante para os corpos de prova de CP IV RS 
SILVA,M. S. A.; BONATTO, A. M.; ZANDONA, J., AVALIAÇÃO DA VARIAÇÃO DIMENSIONAL DE CORPOS DE PROVA DE ARGAMASSA DE DIFERENTES TIPOS DE CIMENTO SUBMETIDOS AO ATAQUE POR ÁCIDO SULFÚRICO E SULFATO DE SÓDIO. $2^{\circ}$ Simpósio Paranaense de Patologia das Construções (20 SPPC), artigo 2SPPC1034, pp. 406-420, 2017. DOI:

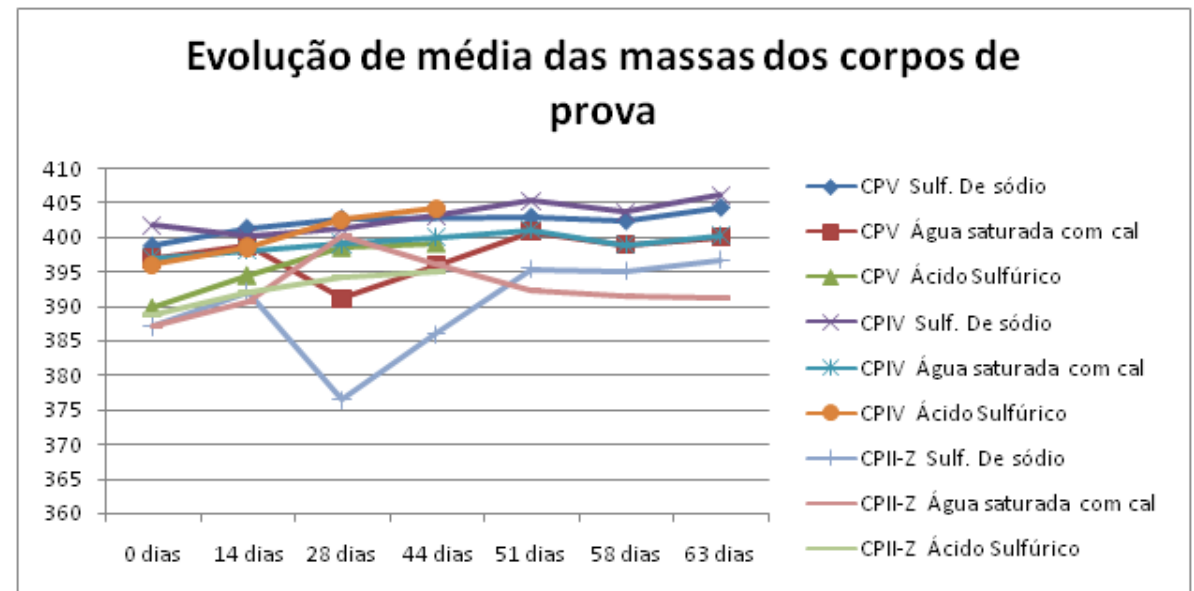

Figura 5: Variação da massa dos corpos de prova expostos a soluções agressivas de sulfatos.

\section{$3.4 \mathrm{pH}$ da solução}

Com a imersão dos corpos de prova nas soluções, alguns compósitos de cimento são dissolvidos e ocorre a dissolução dos mesmos na solução. Com a dissolução dos compostos do cimento ocorre, ainda, a alteração do valor de $\mathrm{pH}$ da solução. Sendo que com 14 dias de exposição o pH da solução de ácido sulfúrico para os três tipos de cimento foi de ácida $(\mathrm{pH}=2,0)$ para básico $(\mathrm{pH}=8,0)$.

Como as soluções de ácido sulfúrico foram as que tiveram maior alteração, mesmo que os corpos de prova tenham sido expostos por pouco tempo, foi realizada a correção do pH das mesmas, conforme já foi descrito Chang et al. [8], que realizaram a correção do $\mathrm{pH}$ das soluções para que a mesma continuasse reagindo mesmo com os compostos da amostra neutralizando a solução. Na solução de ácido sulfúrico, após 14 dias de imersão dos corpos de prova de cimento CP IV-32 RS, houve a precipitação de sólidos, possivelmente decorrente da decomposição dos compósitos de cimento.

Nas soluções de sulfato de sódio e de água saturada com cal houve pouca variação no $\mathrm{pH}$ da solução, sendo uma variação de aproximadamente 1,0 para ambas as soluções. Além disso, não houve variação visível na cor da solução de água saturada com cal e de sulfato de sódio, diferentemente do que ocorreu com a solução de ácido sulfúrico.

Dessa maneira, é possível verificar que a solução de ácido sulfúrico $1 \%$ está reduzindo a quantidade de compostos alcalinos dos corpos de prova de argamassa, uma vez que o ácido sulfúrico reage com a pasta de cimento neutralizando os compostos, conforme verificado por Girardi e Di Maggio [14], que ao utilizarem agregados calcários e silicosos no concreto verificaram que os agregados calcários, com composição básica, teriam capacidade de neutralizar 0 ácido às áreas rodeadas pelo concreto. Dessa maneira, a composição alcalina do concreto teria o mesmo comportamento que foi comprovado pela neutralização das soluções de imersão 
SILVA,M. S. A.; BONATTO, A. M.; ZANDONA, J., AVALIAÇÃO DA VARIAÇÃO DIMENSIONAL DE CORPOS DE PROVA DE ARGAMASSA DE DIFERENTES TIPOS DE CIMENTO SUBMETIDOS AO ATAQUE POR ACIDO SULFURICO E SULFATO DE SODIO. $2^{\circ}$ Simpósio Paranaense de Patologia das Construções (20 SPPC), artigo 2SPPC1034, pp. 406-420, 2017. DOI:

\subsection{Análise visual dos corpos de prova}

$\mathrm{Na}$ análise visual dos corpos de prova imersos em solução de ácido sulfúrico aos 7 dias de exposição foi verificado que para os corpos de prova de cimento CP IV RS houve pouca variação nas primeiras idades, podendo ainda afirmar que os mesmos apresentaram inalterados em relação ao aspecto apresentado no início do ensaio. $\mathrm{Na}$ Figura 6a e Figura 6b é possível observar os corpos de prova de argamassa após a exposição ao ácido sulfúrico por sete dias.
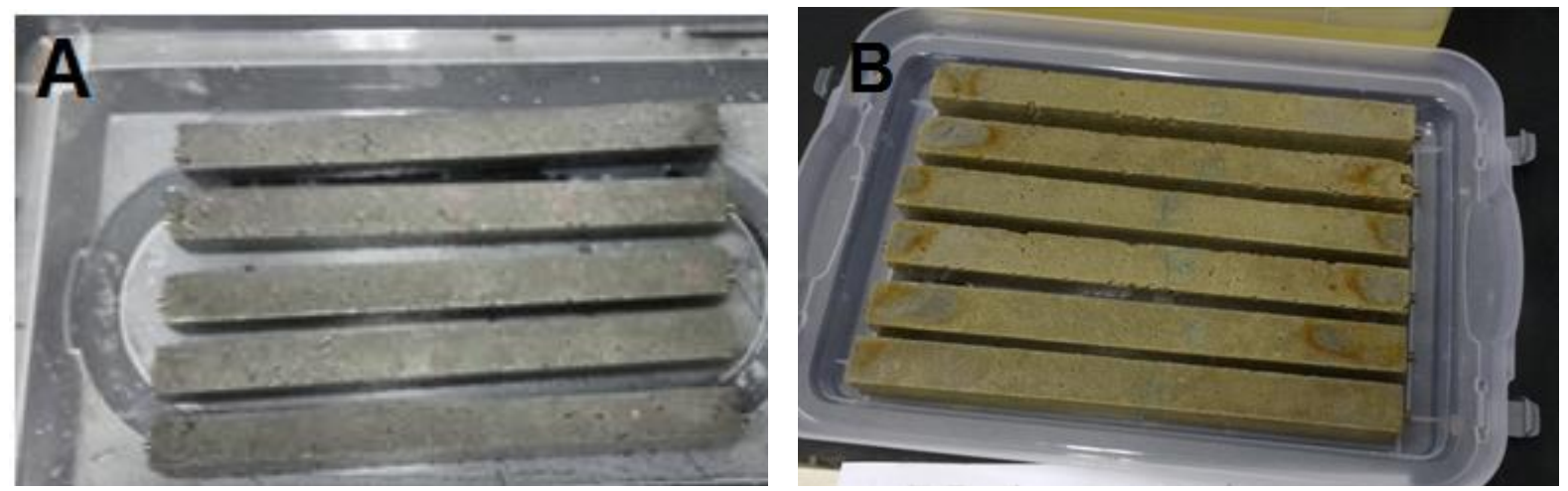

Figura 6a e Figura 6b: Corpos de prova moldados com cimento CP IV-32 RS e CP II $Z$, respectivamente, após 7 dias de imersão em ácido sulfúrico

No entanto, para os corpos de prova de CP II Z houve variação no aspecto dos corpos de prova já nos primeiros dias, uma vez que a coloração da solução de imersão se tornou amarelada, assim como a coloração dos corpos de prova. Além disso, os corpos de prova apresentaram coloração marrom avermelhada nas extremidades, o que poderia indicar início do processo de corrosão dos pinos de aço inox, embora, a corrosão do aço inox seja improvável.

O mesmo aspecto amarelado do concreto e manchas marrom avermelhadas para os corpos de prova pôde ser verificado nos corpos de prova de CP V, como é possível observar na Figura 7, que apresentaram também aspecto áspero da pasta de cimento, que no início do ensaio tinha aspecto liso.

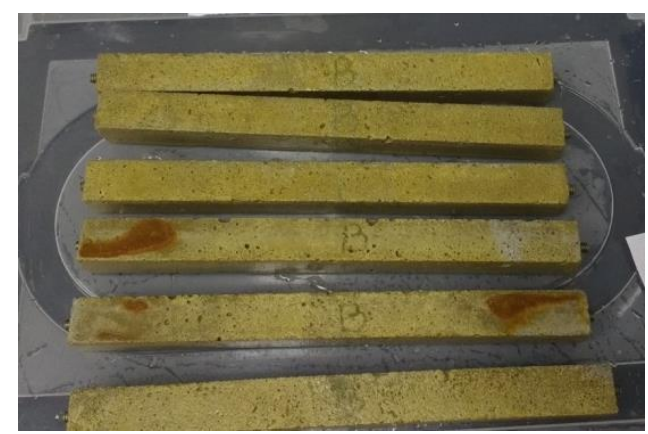

Figura 7: Corpos de prova moldados com cimento CP V, após 7 dias de imersão em ácido sulfúrico, face $B$

Nos corpos de prova imersos em solução de ácido sulfúrico é possível observar a alteração na porosidade e na coloração dos corpos de prova de argamassa com apenas sete dias em imersão. As faces dos corpos de prova, que estavam anteriormente lisas, se apresentam ásperas após o ataque por ácido sulfúrico. 
SILVA,M. S. A.; BONATTO, A. M.; ZANDONA, J., AVALIAÇÃO DA VARIAÇÃO DIMENSIONAL DE CORPOS DE PROVA DE ARGAMASSA DE DIFERENTES TIPOS DE CIMENTO SUBMETIDOS AO ATAQUE POR ÁCIDO SULFÚRICO E SULFATO DE SÓDIO. $2^{\circ}$ Simpósio Paranaense de Patologia das Construções (20 SPPC), artigo 2SPPC1034, pp. 406-420, 2017. DOI:

\section{Considerações finais}

Os corpos de prova moldados com cimento de maior teor de adição (CP IV-32 RS) tiveram a menor variação dimensional frente aos ataques submetidos, sulfato de sódio e ácido sulfúrico. Também foi observado comportamento divergente entre os corpos de prova atacados por ácido sulfúrico, frente aos por sulfato de sódio, sendo que os primeiros, na concentração utilizada, sofreram o de ataque mais intenso.

Os diferentes tipos de cimento utilizados resultaram em valores diferentes de variação dimensional frente ao ataque de ácido sulfúrico. Com relação aos corpos de prova imersos em solução de hidróxido de sódio, os valores máximos de variação dimensional observados no período da realização dos ensaios foram de: CP V - 0,93\%, CP IV-32 RS - 0,349\% e CP II-Z - 1,003\%, ficando os valores do CP IV-32 RS cerca de um terço dos demais.

Quanto ao ensaio de perda de massa, foi verificado que os corpos de prova imersos em solução de ácido sulfúrico tiveram um ganho de massa de $2 \%$ em relação ao início do ensaio, enquanto os corpos de prova imersos em solução de sulfato de sódio e água saturada com cal tiveram um ganho de massa inicial de $1 \%$. Verificase, ainda, que não ocorreu perda de massa significativa nos corpos de prova imersos em ácido sulfúrico durante o ensaio.

Nos corpos de prova imersos em solução de ácido sulfúrico é possível observar a alteração na porosidade e na coloração dos corpos de prova de argamassa com apenas 7 dias em imersão. As faces dos corpos de prova, que estavam anteriormente lisas, se apresentam ásperas após o ataque por ácido sulfúrico.

Os corpos de prova imersos em soluções de sulfato de sódio e água saturada com cal não apresentaram degradação tão avançada quanto os corpos de prova imersos no ácido sulfúrico, mesmo após terem ficado mais tempo expostos às soluções agressivas.

Contudo, para avaliar o cimento a ser utilizado em ambientes com a presença de ácido sulfúrico como indústrias, estações de tratamento de esgoto e outros a NBR 13583 não é a mais adequada, pois a norma especifica que os referidos cimentos que seriam resistentes ao sulfato de sódio não são resistentes ao ácido sulfúrico, por exemplo, pois o sulfato de sódio não é tão agressivo quanto o ácido sulfúrico. Dessa maneira, o cimento que não irá sofrer variação dimensional com sulfato de sódio pode ter uma variação acentuada com o ácido sulfúrico.

Portanto, é necessário especificar materiais mais resistentes para locais que estejam sujeitos ao ataque por ácido sulfúrico, sejam eles para o concreto ou para materiais utilizados para a impermeabilização das estruturas. Além disso, a utilização de impermeabilização com materiais cimentícios para este ambiente não seria adequada, uma vez que o cimento perde as propriedades que garantem a durabilidade da estrutura nestes ambientes. 
SILVA,M. S. A.; BONATTO, A. M.; ZANDONA, J., AVALIAÇÃO DA VARIAÇÃO DIMENSIONAL DE CORPOS DE PROVA DE ARGAMASSA DE DIFERENTES TIPOS DE CIMENTO SUBMETIDOS AO ATAQUE POR ÁCIDO SULFÚRICO E SULFATO DE SÓDIO. $2^{\circ}$ Simpósio Paranaense de Patologia das Construções (20 SPPC), artigo 2SPPC1034, pp. 406-420, 2017. DOI:

\section{Agradecimentos}

Os autores expressam a sua gratidão a Universidade Federal do Paraná (UFPR) pela disponibilização do espaço do Laboratório de Estruturas e Materiais (LAME) no campus centro politécnico da UFPR.

\section{Referências}

[1] Zivica, V. (1998). Experimental principles in the research of chemical resistance of cement based materials. Construction and Building Materials. 12. 365-371.

[2] Mehta, P.K.; Monteiro, P.J. (2005). Concrete: microestrutura, propriedades e materiais. 3a edição. São Paulo. Brasil.

[3] NBR 6118 (2014). Projeto de Estruturas de Concreto - Procedimento. Associação Brasileira de Normas Técnicas - ABNT, Rio de Janeiro, Brasil.

[4] NBR 5737 (1992). Cimentos Portland resistentes a sulfatos. Associação Brasileira de Normas Técnicas - ABNT, Rio de Janeiro, Brasil.

[5] NBR 13583 (2014). Cimento Portland - Determinação da variação dimensional de barras de argamassa de cimento Portland expostas às soluções de sulfato de sódio. Associação Brasileira de Normas Técnicas ABNT, Rio de Janeiro, Brasil.

[6] Torri, K.; Kawamura, M. (1994). Effects of fly ash and silica fume on the resistance of mortar to sulfuric acid and sulfate attack. Cement and Concrete Research. 24. 361-270.

[7] NBR 7211 (2009). Agregados para concreto - especificação. Associação Brasileira de Normas Técnicas - ABNT, Rio de Janeiro, Brasil.

[8] Chang, Z. T.; Song, X. J.; Munn, Ro.; Marosszeky, M. (2005). Using limestone aggregates and different cements for enhancing resistance of concrete to sulphuric acid attack. Cement and Concrete Research. 35. 1486-1494.

[9] Girardi, F. Vaona, W. Di Maggio, R. Resistance of different types of concretes to cyclic sulfuric acid and sodium sulfate attack. Cement and Concrete Composites. 2010. Vol.32, no.8, p.595-602.1.

[10] NBR NM 52 (2003). Agregado graúdo - Determinação de massa específica , massa específica aparente e absorção de água. Associação Brasileira de Normas Técnicas - ABNT, Rio de Janeiro, Brasil.

[11] NBR NM 45 (2006). Agregados - determinação da massa unitária e volume de vazios. Associação Brasileira de Normas Técnicas - ABNT, Rio de Janeiro, Brasil.

[12] NBR NM 248 (2003). Agregado em estado solto - determinação da massa unitária.Associação Brasileira de Normas Técnicas - ABNT, Rio de Janeiro, Brasil.

[13] NBR NM 46 (2003). Agregados - Determinação do material fino que passa através da peneira 75 um, por lavagem. Associação Brasileira de Normas Técnicas - ABNT, Rio de Janeiro, Brasil. 
SILVA,M. S. A.; BONATTO, A. M.; ZANDONA, J., AVALIAÇÃO DA VARIAÇÃO DIMENSIONAL DE CORPOS DE PROVA DE ARGAMASSA DE DIFERENTES TIPOS DE CIMENTO SUBMETIDOS AO ATAQUE POR ÁCIDO SULFÚRICO E SULFATO DE SÓDIO.

$2^{\circ}$ Simpósio Paranaense de Patologia das Construções (20 SPPC), artigo 2SPPC1034, pp. 406-420, 2017. DOI:

[14] Girardi, F.; Di Maggio, R. (2010). Resistance of concrete mixtures to cyclic sulfuric acid exposure and mixed sulfates: Effect of the type of aggregate. Cement \& Concrete Composites. 33. 276-285. 